\title{
Theoretical and Numerical Analysis Of the supports for Evacuated Tube Collector
}

\author{
S. L. Pensalwar, R. S. Tamhankar, A. A. Keste \\ (Department of Mechanical Engineering, M. E. S. College of Engineering, S.P.P. University, India)
}

\begin{abstract}
This paper represents theoretical and numerical analysis of the supports for evacuated tube collectors. Evacuated tube collector (ETC) system works on simple principle 'black body absorption'. This paper also contains the study of newly implemented evacuated tube collectors which are metal in glass tubes instead of glass in glass, that is copper in glass evacuated tubes and aluminium in glass evacuated tubes. At present, evacuated tubes going into production of solar water heaters are being imported from China and Taiwan. This is an attempt to replace this import commodity by an indigenous manufacturing technology with improved collection efficiency. The tube size with outer diameter of $58 \mathrm{~mm}$ and length of $1800 \mathrm{~mm}$ with collector area of $0.1044 \mathrm{~m}^{2}$ will be able to increase water temperature by $48^{0} \mathrm{c}$ for volume 10 liters per tube. The supports which are used for supporting the horizontal vessel are saddle supports.
\end{abstract}

Keywords: Evacuated tubes, Horizontal vessel, Saddle supports, Solar system, Thermal collector

\section{Introduction}

All type of vessels have to be supported by different methods. The supports which are used for vertical vessels are bracket, column, skirt or stool while horizontal vessels are supported by saddles. The selection of the type of support is done on the basis of the height and the diameter of the vessel, available floor space, convenience of location, operating temperature and material of construction. Saddles are used to support horizontal vessels as shown in fig.1. These are placed at two positions. Supports in the form of ring are preferable for vessels in which supports at more than two positions are unavoidable. For large thin-walled vessels or vessels under vacuum, which are liable to be weakened by heavy loads of fittings or other supported structures, it is necessary to provide ring supports.

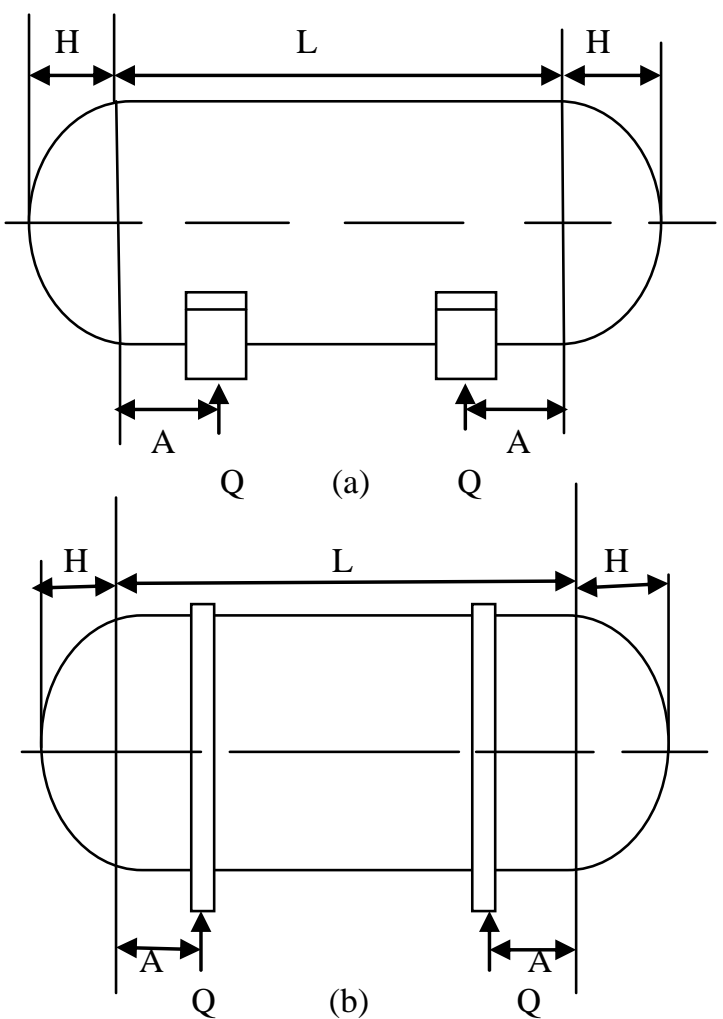

Fig 1. Saddle Supports (a) Plate Type (b) Ring Type 
A solar thermal collector absorbs sunlight by doing that it collects the heat. A collector is a device which captures solar radiation. Solar thermal collectors absorb heat in the form of electromagnetic radiation ranging from the infrared (long) to the ultraviolet (short) wavelengths. The average amount of solar energy striking the Earth's surface (solar constant) is about $1 \mathrm{~kW} / \mathrm{m}^{2}$ under clear skies, depending upon weather, location and orientation. The term "solar collector" commonly refers to solar hot water panels. Simple collectors are typically used in commercial and residential buildings for space heating. One of the most dominant solar thermal systems in operation is the evacuated tube solar thermal system. An evacuated solar system is the most efficient and it gives efficiency of about 70 percent which makes it a common means of solar thermal energy generation. This high efficiency is achieved because of the construction of evacuated tube collector system, meaning they have excellent insulation and are virtually unaffected by air temperatures. The collector itself is made up number of insulated glass tubes. Water is heated in the collector and is then sent through the pipes to the water tank because of the density difference. Because of The presence of supports we can observe two distinct effects on the vessel. Firstly due to internal temperature or pressure change; it interferes with the normal expansion of the vessel secondly the concentrated support reaction results highly localized stresses in the support region [1]. More stress is concentrated in rigid support than a flexible one. the abrupt transition of structural rigidity between the support and the vessel is The main cause of stress concentration. The saddle structure itself is stressed, as all forces acting on the vessel are ultimately transferred to the support. The saddle support will have subsidiary stress and the internal stress of the pressure vessel, therefore saddle support is critical while designing the horizontal type pressure vessel. Therefore the design of the saddle and determination of the stresses induced in it are important steps during the design of horizontal pressure vessel. ${ }^{[2]}$

Solar Energy is an ecological and cost effective alternative to conventional energy supplies ${ }^{[3]}$.A set of evacuated tube solar moderate and high-temperature air heaters with simplified CPC and U-shaped tube heat exchanger provides air with moderate temperature of $150-200^{\circ} \mathrm{C}$ for industrial production ${ }^{[4]}$. This type of solar air heater consists of 10 linked evacuated tube panels. By Experimental study and numerical simulation we can comprehend the thermal performance of the new CPC solar heater. The evacuated tube solar collectors provide a substantial difference in the temperature of the working fluid. The amount of heat transferred to the working fluid depends on the incident flux of solar radiation and on the aperture of the tubes ${ }^{[5]}$. The heat transfer coefficient of the air gap in the tubes plays a major role in facilitating the heat transfer. The main advantage for Heat Pipe Evacuated Tube Solar collector is low heat loss at high temperatures relative to ambient temperature. The design of this collector is simple and easy without the need for sophisticated facilities. If the number of collector is less, the amount of collecting heat will be less ${ }^{[6]}$.In summer season the distance between useful energy gain and solar radiation on tilted surface is less than winter season, which makes the heat loss become less than the winter season ${ }^{[7]}$. Also, instantaneous efficiency and outlet temperature of the collector in warm months is greater than cold months. With the recent advances in vacuum technology, evacuated tube collectors can be reliably mass produced ${ }^{[8]}$. Their high temperature effectiveness is essential to the proper operation of distillation systems. Moreover Thermal losses cause the difference between the consumption energy using solar space heating system by the use of evacuated tubes solar collectors and the gained energy from solar radiation, because of these former mentioned losses from the system, where the main source of heat loss in this system is through the storage $\operatorname{tank}^{[9]}$.

\section{Structure of Evacuated Tube Collectors}

ETC System works on a simple principle 'Black body heat absorption principle'. The principle says, 'black colour absorbs maximum heat, more than any other color'. Solar water heating systems using vacuum tubes made of borosilicate glass with special coating to absorb the solar energy are called as Evacuated Tube Collector system (ETC Systems). Vacuum tube, as shown in the sketch, is the main component, which absorbs solar energy.

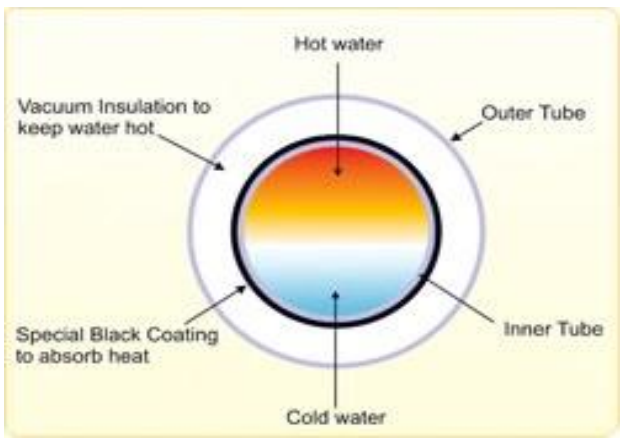

Fig.2 Vacuum (ETC) Tube 
The vacuum tube is an assembly of two concentric, borosilicate glass tubes. Air between the gap of two glass tubes is evacuated. It results in high level of vacuum, which acts as the best insulation to minimize the heat loss from inner tube. The black coating on the inner tube absorbs the solar energy and transfers it to the water. The water on upper side of Vacuum Tube becomes hot and thus lighter, so it starts moving upwards in the tank. At the same time, cold water, which is heavy, comes downward from the tank and is stored at the bottom. The phenomenon is called as natural Thermosyphon circulation, which occurs in every tube.

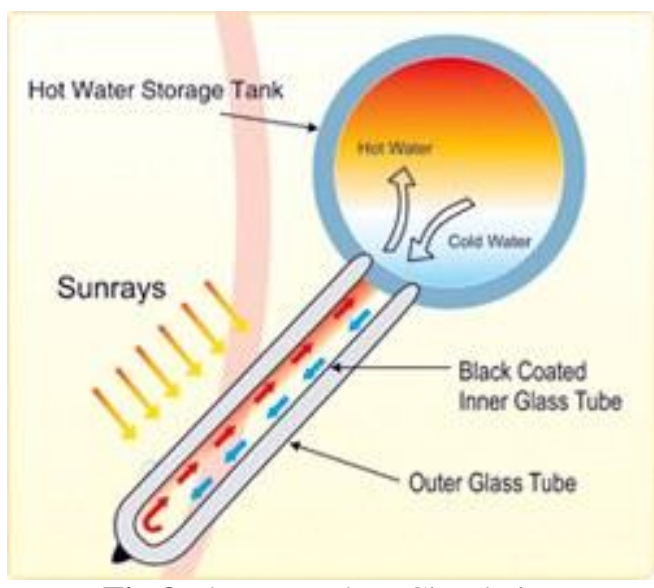

Fig.3 Thermosyphon Circulation

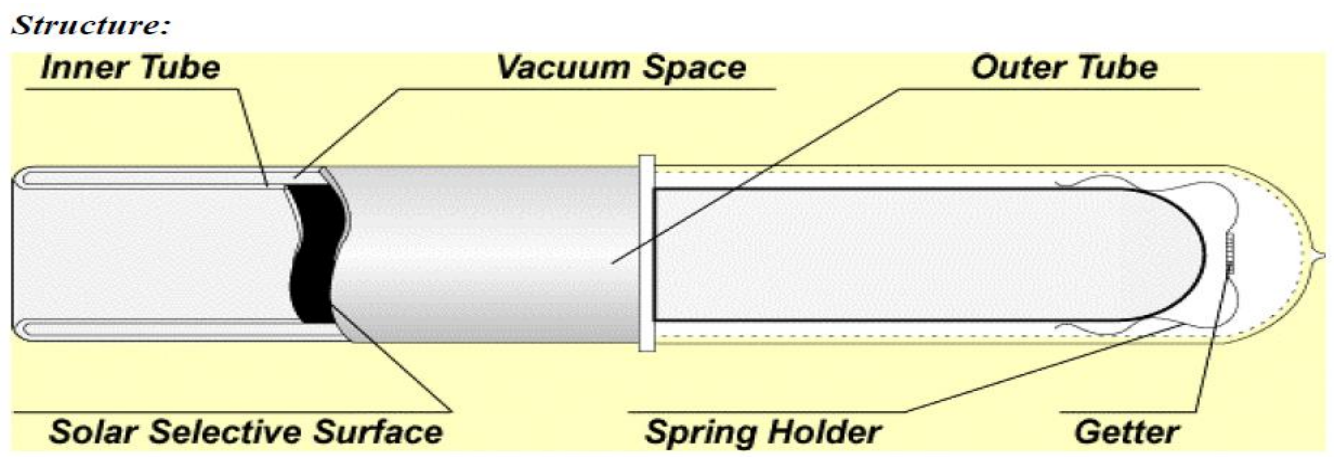

Fig.4 Structure of evacuated tube collector

\section{Analyzing The Problem}

The glass-in-glass tubes have vacuum but has reduced amount of light that reaches the absorber inside. The glass-in-glass system may also faces extensive absorber corrosion because of moisture or condensation forming in the non-evacuated area of the tube. The evacuated tubes which are presently available are the glassin-glass tubes which use two layers of glass fused together at both ends. The newly implemented evacuated tubes are the metal-in-glass tubes. The metal-in-glass combination allows more light to reach the absorber and reduces the chances of moisture corroding the absorber. As metal is a good conductor of heat than glass it increases the collection efficiency of the system. The tubes can be manufactured indigenously and have a salvage value too. The metal-in-glass tubes if damaged can be repaired and they can be recycled.

\subsection{Objectives:}

1. To study design aspects

2. To give better alternative to ETC which can be manufactured indigenously

3. To increase rate of heat transfer

4. To increase efficiency of water heating system

\subsection{To calculate efficiency of ETC:}

\section{Analitical Analysis}

First the collection area and energy collected by one tube per day at $100 \%$ efficiency are calculated. After that the increase in temperature of water for a volume of 10 liters per tube is calculated.

Following are the steps followed for doing the calculations: 
Energy isolation level at Pune (I)

Latitude of the place

Longitude of the place

Average atmospheric Temperature $\left(\mathrm{t}_{\mathrm{atm}}\right)$

Pune is at equatorial belt. The bright sunlight available per day at an average is $8 \mathrm{hr} / \mathrm{day}$

Collection area of ETC tube exposed to sunlight $\left(\mathrm{A}_{\mathrm{c}}\right)=\mathrm{D} * 1$

$$
\begin{aligned}
& =0.058 * 1.8 \\
& =0.1044 \mathrm{~m}^{2}
\end{aligned}
$$

Energy collected by one tube per day at $100 \%$ heat transfer efficiency (Q)

$$
\begin{aligned}
& =0.1044 * 5.245 \\
& =0.5475 \mathrm{kWh} \\
& =471.080 \mathrm{kcal}
\end{aligned}
$$

Therefore, energy collected by one tube per day at $100 \%$ heat transfer efficiency is equal to $471.080 \mathrm{Kcal}$. It is assumed that the volume of water be 10 litres per tube.

As specific weight of water is 1 ,

Mass of water (m)

$$
=10 \mathrm{~kg}
$$

At $100 \%$ thermal efficiency,

$$
\begin{aligned}
Q & =m^{*} c_{p} * \Delta t \\
471.080 & =10 * 1 * \Delta t \\
\Delta t & =47.1080^{\circ} \mathrm{C}
\end{aligned}
$$

Therefore at $100 \%$ thermal efficiency the increase in temperature will be $47.1080^{\circ} \mathrm{C}$ during a day using 8 hrs of bright sunlight.

4.2 Design of tank:

Material - GI

Internal pressure $(\mathrm{p})$

$$
\begin{aligned}
& =1 \mathrm{Kg} / \mathrm{Cm}^{2} \\
& =9.8 * 10^{-2} \mathrm{~N} / \mathrm{mm}^{2}
\end{aligned}
$$

Thickness of tank,

$$
\begin{aligned}
t & =\frac{\left(\rho * D_{i}\right)}{2 * f_{x} * J-\rho} \\
t & =\frac{(0.098 * 380)}{2 * 130 * 0.85-0.098} \\
& =0.1685 \mathrm{~mm}
\end{aligned}
$$

However for rigidity, thickness of $2 \mathrm{~mm}$ sheet is used. And as the tank contains water so to avoid corrosion $2 \mathrm{~mm}$ sheet thickness is used.

As the pressure outside the tank and pressure inside the tank, both are equal therefore we don't need to calculate stress on the tank as the stresses will be negligible.

4.3 Design of support for horizontal vessel:

Material - MS powder coated

Weight of vessel and contents $(w)=$ weight of water + weight of inner tank + weight of

Outer cladding + weight of insulation (puf)

Weight of water

$$
=30 * 9.81
$$

$=294.3 \mathrm{~N}$

$=42 \mathrm{Kg} / \mathrm{m}^{3}$

Weight of insulation (puf)

Volume of insulation

$=$ volume of outer cladding - volume of inner tank

$$
\begin{aligned}
& =\frac{\pi}{4} *\left(480^{2} * 365-380^{2} * 265\right) \\
& =35994797.83 \mathrm{~mm}^{3} \\
& =0.0359 \mathrm{~m}^{3} \\
& =42 * 0.0359 \\
& =14.77644 \mathrm{~N}
\end{aligned}
$$

Weight of outer cladding:

Outer cladding material : GI powder coated

Thickness of outer cladding $: 0.45 \mathrm{~mm}$ 
Density $: 7.86 \mathrm{gm} / \mathrm{cm}^{3}=7.86 * 10^{-6} \mathrm{~kg} / \mathrm{mm}^{3}$

Weight of outer cladding and dish end

$=\left[\left(\pi * 480 * 365 * 0.45 * 7.86 * 10^{-6}\right)+\left(\frac{\pi}{4} * 480^{2} * 0.45 * 2 * 7.86 * 10^{-6}\right)\right] * 9.81$

$$
=31.6148 \mathrm{~N}
$$

Weight of inner tank:

Inner tank material

: GI

Thickness of inner tank

Density

$$
\begin{aligned}
& : 2 \mathrm{~mm} \\
& : 7.86 \mathrm{gm} / \mathrm{cm}^{3}=7.86 * 10^{-6} \mathrm{~kg} / \mathrm{mm}^{3}
\end{aligned}
$$

Weight of inner tank and dish end

$\left[\left(\pi * 380 * 265 * 2 * 7.86 * 10^{-6}\right)+\left(\frac{\pi}{4} * 380^{2} * 2 * 2 * 7.86 * 10^{-6}\right)\right] * 9.81=83.680 \mathrm{~N}$

Therefore,

Weight of vessel and its contents $(w)=294.3+14.77644+31.6148+83.680$

$$
=424.371 \mathrm{~N}
$$

Longitudinal bending moments,

At supports,

$$
M_{1}=Q_{1} A\left[1-\frac{1-\frac{A}{L}+\frac{R^{2}-H^{2}}{2 A L}}{1+\frac{4 H}{3 L}}\right]
$$

At the centre of span,

Data,

$$
M_{2}=\frac{Q_{1} L}{4}\left[\frac{1+2\left(\frac{R^{2}-H^{2}}{L^{2}}\right)}{1+\frac{4 H}{3 L}}-\frac{4 A}{L}\right]
$$

$\mathrm{A}=65 \mathrm{~mm}$

$\mathrm{H}=50 \mathrm{~mm}$

$\mathrm{R}=240 \mathrm{~mm}$

$\mathrm{L}=365 \mathrm{~mm}$

$\mathrm{p}=0.098 \mathrm{~N} / \mathrm{mm}^{2}$

$\mathrm{w}=424.371 \mathrm{~N}$

$\sigma=95 \mathrm{~N} / \mathrm{mm}^{2}$

Stresses in shell at the saddle,

$$
\begin{gathered}
\mathrm{Q}_{1}=\mathrm{w} / 2 \\
=424.371 / 2 \\
=212.18 \mathrm{~N} \\
M_{1}=212.858 * 65\left[1-\frac{1-\frac{65}{365}+\frac{240^{2}-50^{2}}{2 * 64 * 365}}{1+\frac{4 * 50}{3 * 365}}\right] \\
=9334.412 \mathrm{Nmm} \\
M_{2}=\frac{212.080 * 365}{4}\left[\frac{1+2\left(\frac{240^{2}-50^{2}}{365^{2}}\right)}{4 * 65}\right] \\
=16120.34 \mathrm{Nmm}
\end{gathered}
$$

for $\theta=120^{\circ}, \mathrm{k}_{1}=0.107$

At topmost of cross-section,

$$
f_{1}=\frac{M_{1}}{k_{1} * \pi * R^{2} * t}
$$


At bottom most of cross section,

$$
\begin{aligned}
f_{1} & =\frac{9334.412}{0.107 * \pi * 240^{2} * 0.45} \\
& =1.0713 \mathrm{~N} / \mathrm{mm}^{2}
\end{aligned}
$$

for $\theta=120^{\circ}, \mathrm{k}_{2}=0.192$

$$
\begin{aligned}
f_{2} & =\frac{M_{1}}{k_{2} * \pi * R^{2} * t} \\
f_{2} & =\frac{9334.412}{0.192 * \pi * 240^{2} * 0.45} \\
& =0.597 \mathrm{~N} / \mathrm{mm}^{2}
\end{aligned}
$$

The stresses are well within permissible.

Stresses in shell at mid-span,

$$
\begin{aligned}
f_{3} & =\frac{M_{2}}{\pi * R^{2} * t} \\
f_{3} & =\frac{16120.34}{\pi * 240^{2} * 0.45} \\
& =0.19796 \mathrm{~N} / \mathrm{mm}^{2}
\end{aligned}
$$

Axial stress in the shell due to internal pressure,

All the stresses are well within the permissible.

$$
\begin{aligned}
f_{p} & =\frac{\rho * D_{0}}{4 * t} \\
f_{p} & =\frac{0.098 * 480}{4 * 0.45} \\
& =26.133 \mathrm{~N} / \mathrm{mm}^{2}
\end{aligned}
$$

\section{Numerical Analysis}

The numerical analysis is done using the ANSYS software. ANSYS Mechanical is a finite element analysis tool for structural analysis. It includes linear, nonlinear and dynamic studies. This software provides finite elements to the model behavior, and supports material models and equation solvers for almost every mechanical design problems. It also includes thermal analysis and coupled-physics capabilities involving acoustics, piezoelectric, thermal-structural and thermo-electric analysis. To do the numerical analysis of support, a model was created and by using the ANSYS software the support analysis was done. The Fig.5 shows displacement analysis of supports, Fig.6 shows stress analysis of supports, Fig7 shows strain analysis of supports.

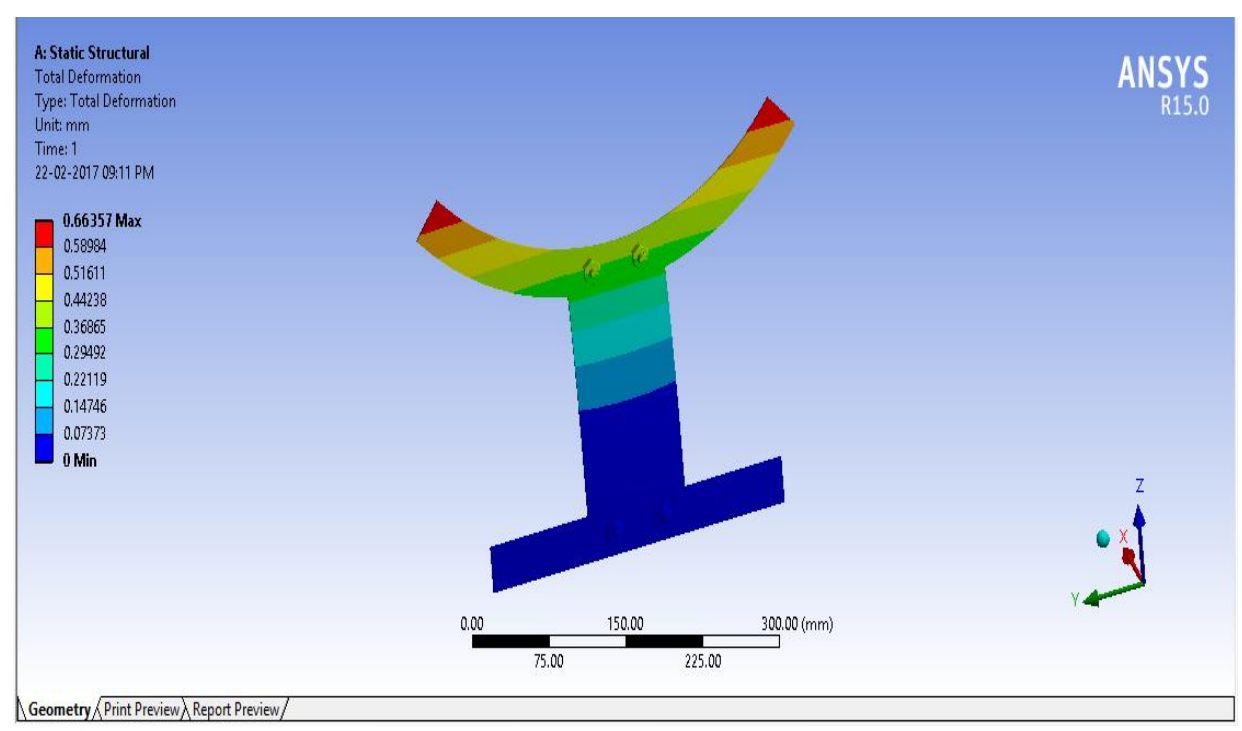

Fig.5 Displacement analysis of support 


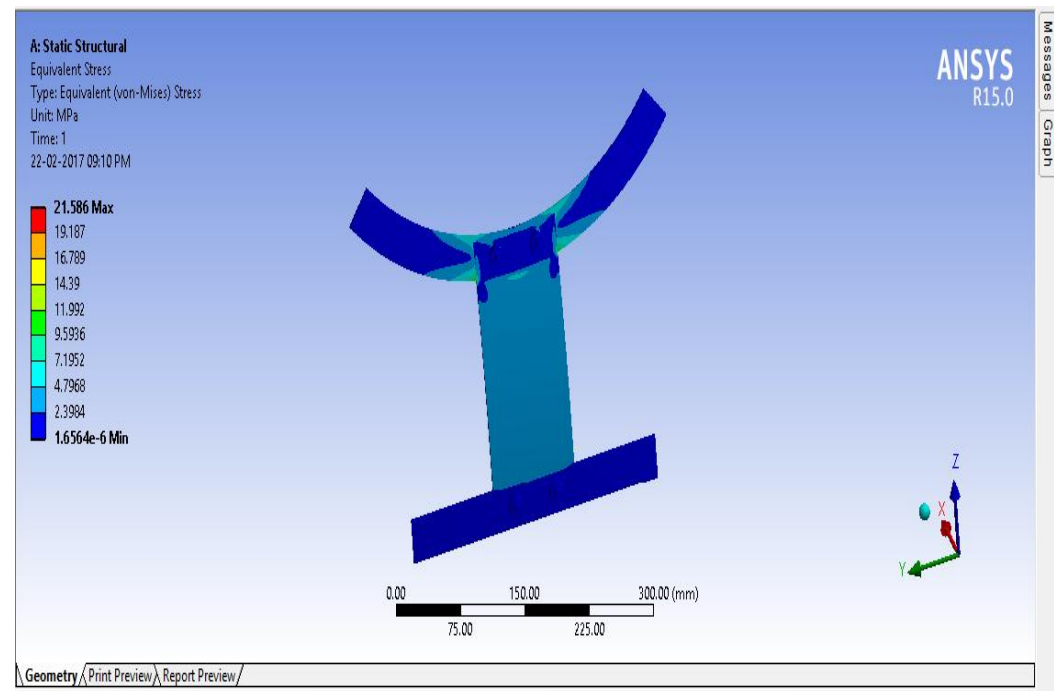

Fig.6 Stress analysis of support

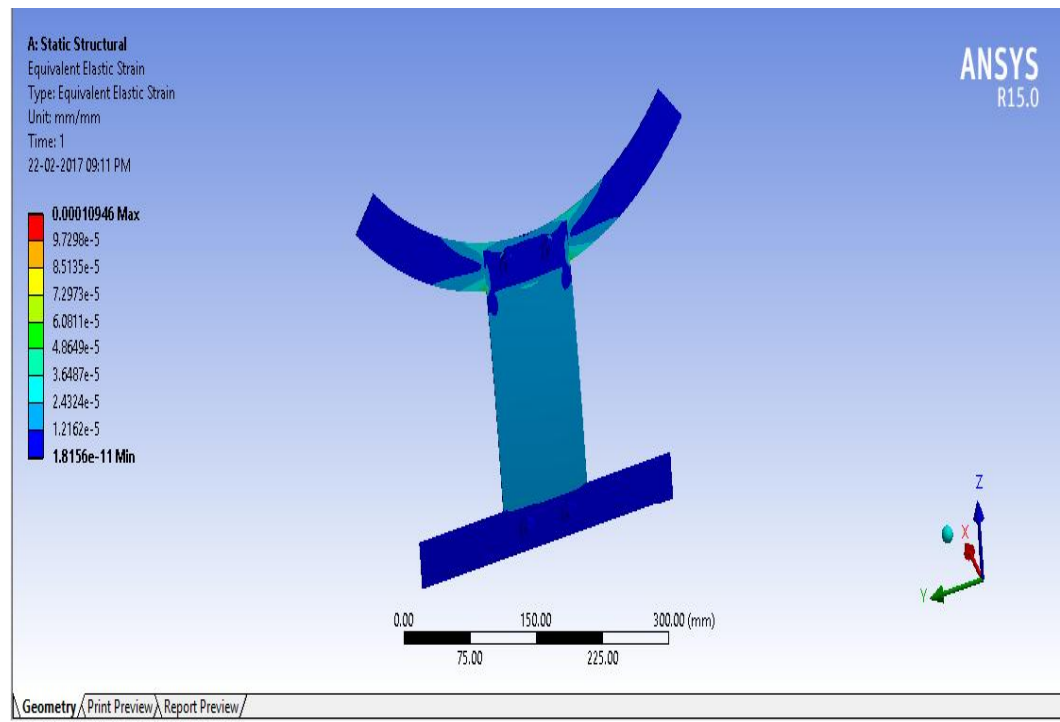

Fig.7 Stain analysis of support

\section{Results And Discussions}

According to Fig.5, the maximum displacement of support is $0.66357 \mathrm{~mm}$. According to Fig.6, the maximum stress induced in the supports is $21.596 \mathrm{~N} / \mathrm{mm}^{2}$. The maximum stress by analytical analysis is 26.133 $\mathrm{N} / \mathrm{mm}^{2}$. Comparing both the stresses with permissible stress, both are within the limits.

The tube size with outer diameter of $58 \mathrm{~mm}$ and length of $1800 \mathrm{~mm}$ with collector area of $0.1044 \mathrm{~m}^{2}$ will be able to increase water temperature by $48^{\circ} \mathrm{c}$ for volume 10 liters per tube.

\section{Conclusion}

At this stage, theoretical and numerical analysis of saddle supports for evacuated tube collectors is done. An alternative to conventional evacuated tubes is given which is more efficient and can be manufactured indigenously. The evacuated tube with collector area $0.1044 \mathrm{~m}^{2}$ will be able to increase water temperature by $48^{\circ} \mathrm{CFor}$ a volume of 10 liters per tube in a day.

\section{References}

[1] P. Pudke, S. B. Rane ,Design and Analysis of Saddle Support: a case study in vessel, Design and Consulting Industry, International Journal of Mechanical Engineering and Technology (IJMET), 4(5) 2013,.139-149.

[2] Adithya M., M. M. Patnaik, Finite element analysis of horizontal reactor Pressure vessel supported on saddles, International Journal of Innovative Research in Science, Engineering and Technology (IJIRSET),2(7) 2013. 
[3] Z. He, AdvancedEvacuated Tube Solar Collectors Products and Applications,Tech Monitor,Beijing Solar Energy Research Institute, Nov-Dec 2003

[4] P. Y. Wang, H.Y. Guan, Z. H. Liu, G.S. Wang ,High Temperature Collecting Performance of a New All-Glass Evacuated Tubular Solar Air Heater With U-shaped Tube Heat Exchanger, Energy Conversion and Management, 77,2013, 315-323.

[5] S. Arora1, S. t. Chitkara1, R. Udayakumar and M. Ali ,Thermal Analysis of Evacuated Solar Tube Collectors, Journal of Petroleum and Gas Engineering, 2(4),2011, 74-82.

[6] S. Hlain ${ }^{\mathrm{g} 1}$, M. M. So ${ }^{\mathrm{e} 2 \text { " }}$ Design Calculation and Heat Transfer Analysis of Heat Pipe Evacuated Tube Solar Collector for Water Heating,International Journal of Scientific Engineering and Research Centre, 3(12), 2014,2606-2611

[7] A.Mohammadkarim, A.Kasaeian, A.Kaabinejadian ,Performance Investigation of Solar Evacuated Tube Collector, International Journal Of Renewable Energy Research Kasaeian et al,4(2), 2014

[8] Ali M. El-Nashar,Evacuated Tube Collectors, Renewable Energy Systems And Desalination,Vol2.

[9] A. I. Owaid ${ }^{1}$, M. Tariq ${ }^{2}, \mathrm{H}$. Issa ${ }^{3}, \mathrm{H}$. Sabeeh ${ }^{4} \&$ M. Ali ${ }^{5}$,The Heat Losses Experimentally in The Evacuated Tubes Solar Collector SystemIn Baghdad-Iraq Climate, International Journal of Research in Engineering \& Technology (IMPACT: IJRET) ,2(4) 2014, 13-24

[10] A. Aboulmag, A. Padova, R. D. Olivesk, D. Del Co,A New Model for The Analysis of Performance in Evacuated Tube Solar Collectors, 3rd International High Performance Buildings Conference at Purdue, 2014 